\title{
GABAergic Inhibition Gates Perceptual Awareness During Binocular Rivalry
}

\author{
(ㄱ) Jeff Mentch, ${ }^{1,2 \star}$ Alina Spiegel, ${ }^{3 \star}$ Catherine Ricciardi, ${ }^{4}$ and ${ }^{\circledR C}$ Caroline E. Robertson ${ }^{1}$ \\ ${ }^{1}$ Department of Psychological and Brain Sciences, Dartmouth College, Hanover, New Hampshire 03755, ${ }^{2}$ McGovern Institute for Brain Research, \\ Massachusetts Institute of Technology, Cambridge, Massachusetts 02139, ${ }^{3}$ School of Medicine, Johns Hopkins University, Baltimore, Maryland, 21205 , and \\ ${ }^{4}$ Clinical Research Center, Massachusetts Institute of Technology, Cambridge, Massachusetts 02139
}

Binocular rivalry is a classic experimental tool to probe the neural machinery of perceptual awareness. During rivalry, perception alternates between the two eyes, and the ebb and flow of perception is modeled to rely on the strength of inhibitory interactions between competitive neuronal populations in visual cortex. As a result, rivalry has been suggested as a noninvasive perceptual marker of inhibitory signaling in visual cortex, and its putative disturbance in psychiatric conditions, including autism. Yet, direct evidence causally implicating inhibitory signaling in the dynamics of binocular rivalry is currently lacking. We previously found that people with higher GABA levels in visual cortex, measured using magnetic resonance spectroscopy, have stronger perceptual suppression during rivalry. Here, we present direct causal tests of the impact of GABAergic inhibition on rivalry dynamics, and the contribution of specific GABA receptors to these dynamics. In a crossover pharmacological design with male and female adult participants, we found that drugs that modulate the two dominant GABA receptor types in the brain, $\mathrm{GABA}_{\mathrm{A}}$ (clobazam) and $\mathrm{GABA}_{\mathrm{B}}$ (arbaclofen), increase perceptual suppression during rivalry relative to a placebo. Crucially, these results could not be explained by changes in reaction times or response criteria, as determined through rivalry simulation trials, suggesting a direct and specific influence of GABA on perceptual suppression. A full replication study of the $\mathrm{GABA}_{\mathrm{B}}$ modulator reinforces these findings. These results provide causal evidence for a link between the strength of inhibition in the brain and perceptual suppression during rivalry and have implications for psychiatric conditions including autism.

Key words: awareness; binocular rivalry; GABA; inhibition; perception; pharma

\section{Significance Statement}

How does the brain accomplish perceptual gating? Here we use a direct and causal pharmacological manipulation to present insight into the neural machinery of a classic illusion of perceptual awareness: binocular rivalry. We show that drugs that increase GABAergic inhibition in the brain, clobazam $\left(\mathrm{GABA}_{\mathrm{A}}\right.$ modulator) and arbaclofen $\left(\mathrm{GABA}_{\mathrm{B}}\right.$ modulator), increase perceptual suppression during rivalry relative to a placebo. These results present the first causal link between GABAergic inhibition and binocular rivalry in humans, complementing classic models of binocular rivalry, and have implications for our understanding of psychiatric conditions, such as autism, where binocular rivalry is posited as a behavioral marker of disruptions in inhibitory signaling in the brain.

\section{Introduction}

Perception is often at odds with retinal input. Even highly salient stimuli are sometimes "edited out" of our perceptual experience,

Received April 12, 2019; revised July 28, 2019; accepted Aug. 12, 2019.

Author contributions: C.R. and C.E.R. designed research; J.M., A.S., C.R., and C.E.R. performed research; C.E.R. analyzed data; J.M., A.S., C.R., and C.E.R. wrote the paper.

This work was supported by a Grant from the Simons Foundation Autism Research Initiative (SFARI 597694) to C.E.R. We thank Anna Weinstein, Caitlin Van Wicklin, and Tatiana Urman for their help with data collection and

Thomas Botch for helpful comments on drafts; the editor and reviewers for comments and suggestions.

The authors declare no competing financial interests.

*J.M. and A.S. contributed equally to this work.

Correspondence should be addressed to Caroline E. Robertson at caroline.e.robertson@dartmouth.edu.

https://doi.org/10.1523/JNEUROSCI.0836-19.2019

Copyright $\odot 2019$ the authors particularly when they are in conflict with probable interpretations of the external environment. How does the brain accomplish such acute and effective perceptual suppression?

Binocular rivalry is a classic test of perceptual suppression. During rivalry, two images, one presented to each eye, vie for perceptual awareness (Leopold and Logothetis, 1996; Tong et al., 2006; Xu et al., 2016). This alternation in perception is modeled to rely on the strength of inhibitory interactions between competitive neuronal populations in visual cortex (Fig. 1A). Specifically, the strength with which an image is suppressed from awareness is thought to be governed by reciprocal inhibition across neuronal populations coding for each eye's percept at multiple stages of visual processing (Blake, 1989; Laing and Chow, 

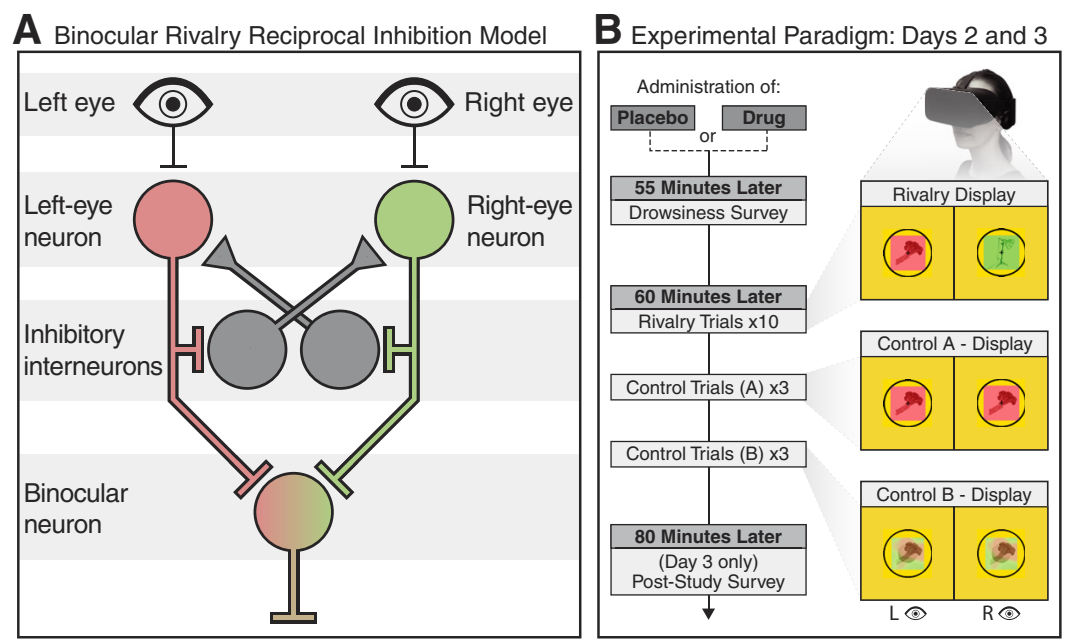

Figure 1. Binocular rivalry model and experimental paradigm. $A$, Schematic model of rivalry circuitry. During binocular rivalry, two images, one presented to each eye, alternate back and forth in awareness. This perceptual experience is hypothesized to reflect the activity of competing pools of left-eye and right-eye neurons, which cross-inhibit each other in alternation, presumably via inhibitory interneurons. The strength of cross-inhibition is hypothesized to govern the strength with which an image is suppressed from awareness. $B$, Participants took part in a double-blind crossover design study to test the effect of drugs which increase GABAergic inhibition on perceptual suppression during rivalry. After an initial study visit (Day 1; see Materials and Methods), participants returned for two experimental testing days (Day 2 and Day 3). On each experimental day, participants were first administered either a drug or a placebo pill. Subsequently, participants began experimental testing, completing binocular rivalry and control rivalry simulation trials (see Materials and Methods; Movies 1, 2). Control A trials provided us with an estimate of participants' motor response latencies (how quickly they press and release a button in response to a stimulus change on the screen). Control B trials provided us with an estimate of participants' perceptual decision criteria (the percentage mixture of a stimulus for a participant to report either a mixed or a dominant percept).

2002; Noest et al., 2007; Seely and Chow, 2011; Said and Heeger, 2013; van Loon et al., 2013; Li et al., 2017). Models of rivalry consequently predict that increasing inhibition will increase the strength of perceptual suppression (Klink et al., 2010; Said et al., 2013), decreasing the proportion of rivalry periods where one of the two images is not fully suppressed from awareness (mixed percepts). Magnetic resonance spectroscopy (MRS) data support this prediction: individuals with higher tonic levels of the inhibitory neurotransmitter, GABA, in early visual cortex show increased perceptual suppression during rivalry (Robertson et al., 2016) and shorter dominant percept durations (van Loon et al., 2013; Pitchaimuthu et al., 2017). Further, the dynamics of two other bistable phenomena that are often thought of as computationally related to rivalry (but see Gallagher and Arnold, 2014; Brascamp et al., 2018), motion-induced-blindness and structurefrom-motion, have been shown to causally depend on the strength of inhibition in the brain using a pharmacological manipulation (van Loon et al., 2013) and to correlate with GABA levels in visual cortex (but see Sandberg et al., 2016). Despite these results, however, direct causal evidence linking GABAergic inhibition to binocular rivalry dynamics is currently lacking. Further, the specific branches of the GABAergic pathway that might contribute to rivalry dynamics are currently unknown.

Identifying a causal link between inhibition and binocular rivalry holds translational implications for psychiatric research, given recent observations of altered binocular rivalry dynamics in psychiatric conditions, such as autism (Robertson et al., 2013, 2016; Freyberg et al., 2015). Specifically, individuals with autism evidence weaker perceptual suppression during rivalry and slower switch rates (Robertson et al., 2013, 2016; Freyberg et al., 2015). Magnetic resonance spectroscopy evidence suggests that this replicated difference in rivalry dynamics may stem from a disruption in GABAergic signaling in the autistic brain (Robertson et al., 2016). This hypothesis is consistent with animallevel findings with genetic models of autism, which suggest that disruptions in inhibitory signaling may characterize the autistic brain (Shao et al., 2003; Ma et al., 2005; Fatemi et al., 2009; Gogolla et al., 2009; Sanders et al., 2011; Griswold et al., 2012; Piton et al., 2013; Chen et al., 2014; Orefice et al., 2016; but see Antoine et al., 2019), as well as rivalry model simulation results, which predict that weakening inhibition in the brain would weaken perceptual suppression during rivalry (Klink et al., 2010; Said et al., 2013). Together, this literature suggests that rivalry may index disruptions in inhibitory signaling in visual cortex in autism. But causal evidence linking GABAergic inhibition to rivalry in humans is currently lacking.

Here, we tested whether increasing GABAergic inhibition in the brain strengthens perceptual suppression during rivalry in humans using a randomized, double-blind crossover pharmacological design. We further examined whether specific branches of the GABAergic pathway support rivalry by directly comparing the impact of drugs that target the two dominant $\mathrm{GABA}$ receptor types in the brain, $\mathrm{GABA}_{\mathrm{A}}$ and $\mathrm{GABA}_{\mathrm{B}}$, on rivalry dynamics. In a subsequent replication study, we tested the impact of $\mathrm{GABA}_{\mathrm{B}}$ on rivalry in an independent sample of participants.

\section{Materials and Methods}

Participants. Healthy adult individuals participated in three studies [Study 1: $N=21$; Study 2: $N=22$; Study 3 (replication study): $N=22$; Table 1]. Written consent was obtained from all participants, and all studies were approved by the Massachusetts Institute of Technology Institutional Review Board. All participants had normal or corrected-tonormal vision, were neither pregnant nor nursing, and were free from: (1) any known history of psychiatric or neurological conditions; (2) any other diagnosed medical conditions, including a history of heart failure; (3) any psychiatric medications; and (4) any known drug allergies (including clobazam or arbaclofen). All studies took place at the MIT Clinical Research Center, under the constant observation of a research nurse/ nurse practitioner (C.R.) and nursing team. Because of the experimental nature of the drug used in Studies 2-3, arbaclofen, which is currently classified as an Investigational New Drug by the FDA, this study was monitored by an external drug safety monitor from Tufts Medical Center.

Study drugs: clobazam $\left(G A B A_{A}\right)$ and arbaclofen $\left(G A B A_{B}\right)$. Participants participated in three different studies, investigating the effects of: Study 1 , a $\mathrm{GABA}_{\mathrm{A}}$ modulator (clobazam, $5 \mathrm{mg}$ ); Study 2, a $\mathrm{GABA}_{\mathrm{B}}$ modulator (arbaclofen, $20 \mathrm{mg}$ ); Study 3, a $\mathrm{GABA}_{\mathrm{B}}$ modulator (arbaclofen, $20 \mathrm{mg}$; replication of Study 2) on binocular rivalry dynamics. Clobazam is an FDA-approved GABA modulator, which engages $\mathrm{GABA}_{\mathrm{A}}$ receptors at the 1,5-benzodiazepine site (Hanks, 1979). Arbaclofen (also known as R-baclofen or STX209) is an investigational new drug that engages $\mathrm{GABA}_{\mathrm{B}}$ receptors as a GABA analog (Hill and Bowery, 1981), and is the (R)-enantiomer of baclofen. Clobazam dosage was chosen to fall within the standard dose prescribed range and arbaclofen dosage was determined based on previous studies in children with fragile $\mathrm{X}$ (Berry-Kravis et al., 2012, 2017). 
Table 1. Psychometric data from all participants including age, Autism Quotient (AQ) score, KBIT-2 spatial reasoning IQ score, and gender

\begin{tabular}{|c|c|c|c|c|}
\hline & Minimum & Maximum & Mean & SD \\
\hline \multicolumn{5}{|c|}{ Study $1\left(\mathrm{GABA}_{\mathrm{A}}\right)$ clobazam vs placebo, $N=21$} \\
\hline Age & 18 & 34 & 23.24 & 4.300 \\
\hline 10 & 102 & 132 & 124.71 & 9.804 \\
\hline$A Q$ & 7 & 30 & 18.19 & 6.593 \\
\hline Gender & $8: M$ & 13:F & & \\
\hline \multicolumn{5}{|c|}{ Study $2\left(\mathrm{GABA}_{\mathrm{B}}\right)$ arbaclofen vs placebo, $N=22$} \\
\hline Age & 20 & 31 & 23.36 & 3.317 \\
\hline IQ & 55 & 132 & 119.27 & 16.861 \\
\hline $\mathrm{AQ}$ & 8 & 30 & 19.45 & 5.431 \\
\hline Gender & $8: M$ & 14:F & & \\
\hline \multicolumn{5}{|c|}{ Study $3\left(\mathrm{GABA}_{B}\right)$ arbaclofen vs placebo replication, $N=22$} \\
\hline Age & 18 & 40 & 25.00 & 5.912 \\
\hline IO & 70 & 132 & 114.59 & 14.851 \\
\hline$A Q$ & 5 & 26 & 15.95 & 6.425 \\
\hline Gender & $9: M$ & 13:F & & \\
\hline
\end{tabular}

Experimental design: double-blind placebo-controlled crossover design. Each study took place $3 \mathrm{~d}$ : a health assessment/practice session (Day 1) and 2 experimental days (Days 2 and 3). On each of the experimental days, a participant was given either a drug or a placebo and participated in a short binocular rivalry experiment after the drug had come into effect (Fig. 1B). This within-participant crossover design allowed us to compare the effects of each drug, relative to those of a placebo, on rivalry dynamics. In Study 3, we conducted a direct replication of the doubleblind crossover design of Study 2 with an independent sample of participants.

On Day 1, participants were briefed on the study and completed an informed consent. Once consented, the nurse practitioner (NP) assessed the participant for drug allergies, reviewed the participant's medical history, and completed a routine physical assessment (including blood pressure, temperature, and a basic metabolic panel to assess kidney function) to ensure that participants were healthy enough to participate in the study. Participants were also assessed for colorblindness. All women of childbearing ages were asked to provide a small urine specimen for a urine pregnancy point of care test to confirm non-pregnancy state. Participants also performed six $45 \mathrm{~s}$ rivalry practice trials to become familiarized with the task.

On Days 2 and 3 of testing, each participant received an oral dose of a drug on one day and a matched placebo pill on the other day. Drug day assignment was blinded, randomized, and counterbalanced across participants (i.e., in Study 1, one-half of the participants received a placebo on Day 2 and clobazam on Day 3, whereas the other half received clobazam on Day 2 and a placebo on Day 3). After waiting for a time period to allow for drug absorption and distribution to approximate peak-plasma concentration (60 min; Volz and Kellner, 1980), the participants completed a brief drowsiness scale and performed the binocular rivalry experiment.

Following testing on both Days 2 and 3, the NP performed a physical assessment for adverse events to ensure that each participant was in sufficient health to leave the Clinical Research Center. Additionally, on Day 3, participants answered a series of survey questions regarding their first-person reflections on their rivalry dynamics during the study.

Experimental paradigm. Testing sessions were composed of two blocks of five $45 \mathrm{~s}$ experimental runs (binocular rivalry), and six $45 \mathrm{~s}$ rivalry stimulation control trials ( 3 "sudden onset" trials and 3 "gradual onset" trials). During rivalry trials, two different images (red or green) were presented to participants' left and right eyes. During rivalry simulation trials, identical images were continuously presented to both eyes, alternating temporally on the screen (Movies 1,2). Participants were asked to continuously report whether they perceived a fully dominant percept, the red image (right key) or the green image (left key), or a mixture of the two images (up key). Percept durations as well as switch rates were analyzed during rivalry and simulation trials.

Binocular rivalry experiment: stimuli and analysis. Binocular rivalry stimuli and analysis were identical to those used in our previously pub-

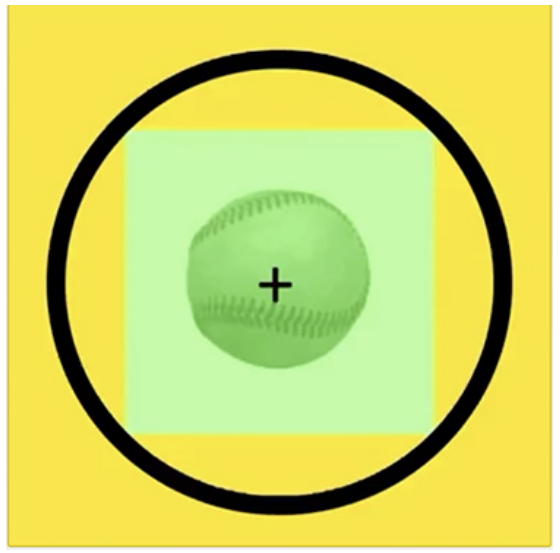

Movie 1. Example of rivalry simulation control trials (sudden transitions, Control A). Participants viewed stepwise, sudden transitions between two stimuli, which allowed us to determine response latencies to clear, obvious transitions. The rate of these transitions followed rivalry transitions from a previous study using the same stimuli (Robertson et al., 2013).
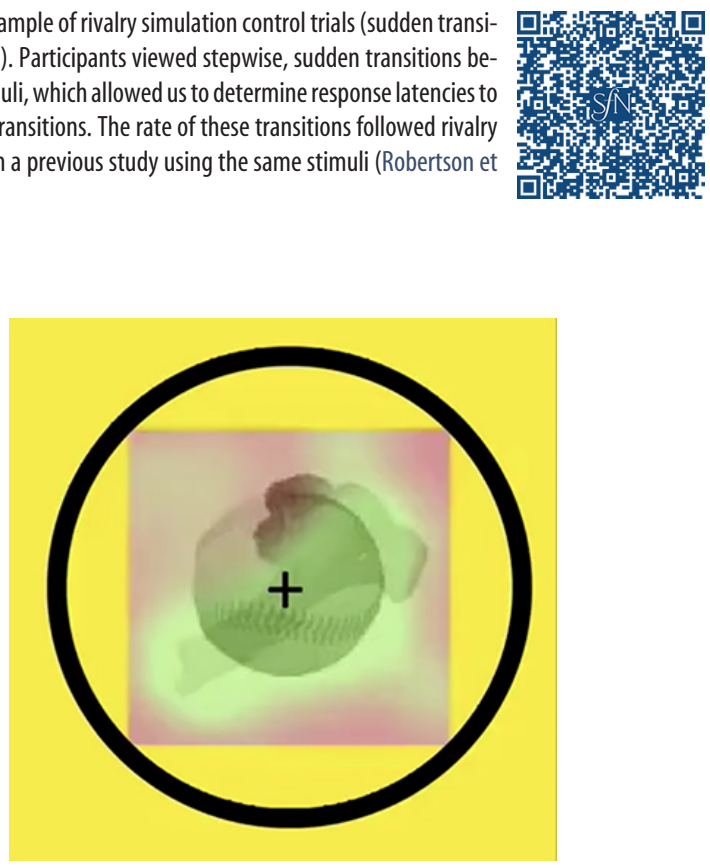

Movie 2. Example of rivalry simulation control trials (gradual transitions, Control B). Gradual transition trials provided us with an estimate of participants' perceptual decision criteria: the extent of image blending each individual required to identify an image as mixed versus dominant. Participants viewed gradual, linear transitions between stimuli created using a series of dynamic Gaussian image filters. Specifically, 列 mined by 15 Gaussian filters, which were distributed randomly within the image. As in Control $A$, the rate of these transitions followed rivalry transitions from a previous study using the same stimuli (Robertson et al., 2013).

lished studies (Robertson et al., 2013, 2016), except that the stimuli were slightly larger to avoid possible ceiling effects by increasing the expected incidence of mixed percepts (Blake et al., 1992). On each run, two grayscale objects (e.g., a baseball and a piece of broccoli) appeared on the left and right of the screen. Stimuli were drawn from the Bank of Standardized Stimuli (Brodeur et al., 2014) and the subset of stimuli used in our study can be viewed at https://osf.io/bhgyd. Each object was displayed within a tinted square (green or red; width: $5.3^{\circ}$ ), surrounded by a black circle to support binocular fusion (radius: $3.7^{\circ}$ ). Participants were instructed to fixate on a cross at the center of each image. Stimuli were viewed through a head-mounted display (Oculus Rift CV1; $1080 \times 1200$ pixels per eye, $90 \mathrm{~Hz}$ refresh rate, $\mathrm{FOV}=110^{\circ}$ ), which displayed the left and right halves of the screen to the participants' left and right eyes such that each eye was presented with only one of the two images (red or green; Fig. 1B). Data, materials, and code are available upon request. 
Keypresses were sampled every $4 \mathrm{~ms}$, and a sequence of perceptual events was later computed based on when one continuous key press was terminated and another began. Keypresses lasting $<400 \mathrm{~ms}$ or periods where no key was pressed were omitted from the analysis. For each participant and trial, the frequency of perceptual transitions as well as the duration of any perceptual event (red, green, or mixed) were calculated. Transitions were subdivided into two classes: "switches" (e.g., red to mixed to green) or "reversions" (e.g., red to mixed to red). Participants were instructed to initiate each trial by pressing and holding down the up key until they first saw a dominant percept (red or green). This initial keypress corresponding to "onset rivalry" (Stanley et al., 2011) was not considered in the analysis. Including short keypresses or onset rivalry periods did not qualitatively affect the results.

Rivalry simulation trials: paradigm and analysis. Binocular rivalry simulation trial stimuli were identical to those used in the main rivalry experiment, and the paradigm was identical to our previously published studies (Robertson et al., 2013; Movies 1 and 2). In brief, participants viewed a simulated series of back-and-forth binocular rivalry alternations as in (Baker and Graf, 2009; Robertson et al., 2013). The stimuli were presented using exactly the same setup and stimulus parameters as in the rivalry trials but, unlike rivalry, identical images were continuously presented to both eyes, presented in temporal back-and-forth alternation on the screen for the duration of the trial. Thus, in these trials, we measured participants' responses to physical changes in the stimuli, rather than perceptual changes associated with binocular rivalry.

These trials allowed us to measure two non-perceptual factors which could, in theory, contribute to any observed drug effects on rivalry: response latencies (Control A) and response criteria (Control B). In sudden-onset trials (Control A), participants viewed stepwise, sudden transitions between two stimuli, which allowed us to determine response latencies to clear, obvious transitions. In gradual-onset trials (Control B), participants viewed gradual, linear transitions between stimuli created using a series of dynamic Gaussian image filters. Specifically, during a transition, the proportion of either dominant image displayed at any pixel was determined by 15 Gaussian filters, which were distributed randomly within the image. This allowed us to determine participants' response criteria: the extent of image blending each individual required to identify an image as mixed versus dominant.

In all control trials, the presentation durations of on-screen events (dominant or mixed on-screen images) were based on data from a previous rivalry study in our laboratory (Robertson et al., 2013). Specifically, we took all percept durations reported in that previous study, created a distribution of percept durations for each percept type, and randomly drew from this distribution to create a simulated series of back-and-forth rivalry alternations. We clipped this duration distribution to eliminate extreme values to ensure that participants had ample time to report each event, and to allow for sufficient back-and-forth alternations. In sudden onset (Control A) trials, the mean presentation duration of on-screen events was $1.96 \mathrm{~s}, \pm 0.69 \mathrm{SD}$ (min: $1 \mathrm{~s}$, max: $3 \mathrm{~s}$ ). From event onset, $2 \mathrm{~s}$ was allocated for the correct response to occur (left or right key). To ensure the response corresponded to the event in question, only correct button presses were logged. If no correct button press occurred within that time frame ( $<1 \%$ of events), no button press was logged. Similarly, in gradual onset (Control B) trials, the mean duration of mixture transitions was 1.85 , $\pm 1.02 \mathrm{SD}$ (min: $0.51 \mathrm{~s}$, max: $4.99 \mathrm{~s}$ ). To ensure the response corresponded to the transition event in question, only correct button presses that occurred during the on-screen transition were logged. If no correct button press occurred within that time frame ( $<2 \%$ of events), no button press was logged.

Perceptual suppression metric. Perceptual suppression during rivalry is experienced by the viewer as an increased proportion of dominant percepts, compared with mixed percepts. Thus, the primary measure of interest, the proportion of perceptual suppression, was calculated as the proportion of each trial spent viewing a fully dominant percept: (dominant percept durations)/(dominant + mixed percept durations).

Statistical analyses. Data reported in all ANOVAs was normally distributed (Shapiro-Wilk test; all $p>0.359$ ). Two-tailed, uncorrected $p$ values are reported for all repeated-measures ANOVAs and spearman's rank correlation coefficients $(R s)$ are reported for all effects. For each partici- pant, trials where rivalry was never initiated (one percept was reported for the entire trial) were eliminated. Participants missing $>50 \%$ of trials or whose rivalry percept durations were determined to fall outside of 2 $\mathrm{SD}$ of the group mean were excluded from analyses (Study 1: 4 individuals; Study 2: 4 individuals; Study 3: 3 individuals). One participant in Study 2 was excluded due to drowsiness, and one participant in Study 3 was excluded due to extreme dizziness after drug administration. After removing outliers, Study 2 was no longer counterbalanced for study day. To account for this, we conducted post hoc analyses, where we re-ran our main ANOVAs described below, including "study day" as a covariate in our analysis. All reported results remained significant at $p<0.01$.

Psychometric tests and surveys. Immediately before each rivalry session, participants completed the Karolinska sleepiness scale (KSS) to assess any self-reported changes in drowsiness between drug and placebo testing sessions. The KSS consisted of a single question, "Choose the position on the following scale that best describes your current state", where answers ranged from 1 (extremely alert) to 9 (very sleepy, great effort to keep awake, fighting sleep). Participants also completed the Autism Quotient and a brief spatial reasoning IQ test, the KBIT-2 (Kaufman, 1990; Table 1).

After the final testing session on Day 3, participants completed a poststudy survey to assess: (1) "On which day do you think you received the drug and why?", (2) "Did you notice any differences in your experience of binocular rivalry between yesterday and today? If so, please describe.", (3) "How confident were you in determining whether you were seeing a mixture or a dominant state?", and (4) "Describe what mixtures during binocular rivalry look like to you."

\section{Results}

We predicted that drugs that increase inhibition in the brain $\left(\mathrm{GABA}_{\mathrm{A}}\right.$ modulator, clobazam, and $\mathrm{GABA}_{\mathrm{B}}$ modulator, arbaclofen) would increase perceptual suppression during rivalry. We directly compared these effects to rivalry simulation control trials to assess whether any observed changes were due to nonperceptual effects on response latencies or response criteria (Gallagher and Arnold, 2014; Brascamp et al., 2018). Finally, we conducted a direct replication study to test the repeatability of our main effects using the $\mathrm{GABA}_{\mathrm{B}}$ agonist, arbaclofen.

\section{GABA modulators strengthen perceptual suppression}

To quantify the effect of each drug on rivalry dynamics, we used a repeated-measures ANOVA, including Drug Condition (Drug vs Placebo) as a within-subjects factor for each study (Study 1: clobazam; Study 2: arbaclofen). As predicted, individuals reported a higher proportion of perceptual suppression on the drug, compared with the placebo day in both studies (Clobazam vs Placebo: $F_{(1,16)}=5.237, \eta_{\mathrm{p}}^{2}=0.247, p=0.036$. Arbaclofen vs Placebo: $F_{(1,16)}=6.578, \eta_{\mathrm{p}}^{2}=0.291, p=0.021$; Figs. $\left.2 A, 3 A\right)$. In Study 1 (clobazam), this effect was driven by reduced time in mixed percepts on the drug compared with the placebo day per $\operatorname{trial}\left(F_{(1,16)}=6.336, \eta_{\mathrm{p}}^{2}=0.284, p=0.023\right)$; no change to dominant percepts was observed $\left(F_{(1,16)}=0.593, \eta_{\mathrm{p}}^{2}=0.036, p=\right.$ $0.453)$. In Study 2 (arbaclofen), this effect was driven by increased time in dominant percepts on the drug compared with the placebo day per trial $\left(F_{(1,16)}=7.647, \eta_{\mathrm{p}}^{2}=0.323, p=0.014\right)$ and slightly reduced time in mixed percepts $\left(F_{(1,16)}=3.181, \eta_{\mathrm{p}}^{2}=\right.$ $0.166, p=0.093$ ). In Study 3 (arbaclofen replication), we again observed a higher proportion of perceptual suppression on the drug compared with the placebo days $\left(F_{(1,17)}=5.145, \eta_{\mathrm{p}}^{2}=\right.$ $0.232, p=0.037)$, which was driven by increased time in dominant percepts on the drug compared with the placebo day (Dominant percepts: $F_{(1,17)}=5.077, \eta_{\mathrm{p}}^{2}=0.230, p=0.038$; Mixed percepts: $F_{(1,17)}=1.238, \eta_{\mathrm{p}}^{2}=0.068, p=0.281$; Fig. $\left.4 A\right)$. 
A Study 1 - Rivalry Trials

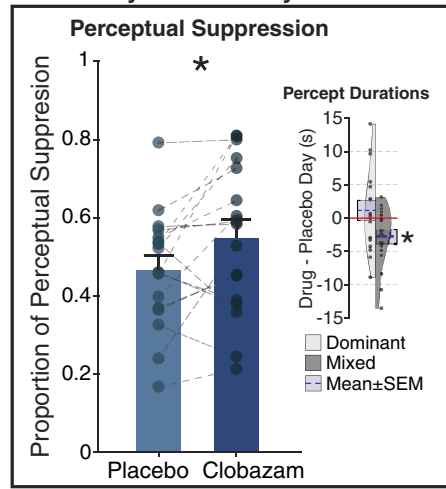

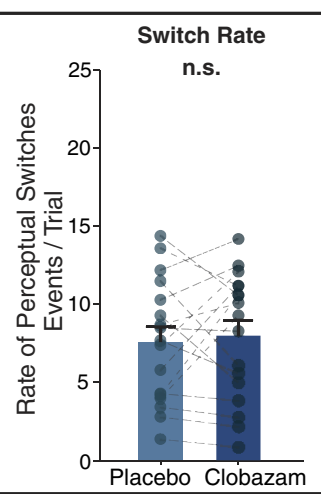

B Study 1 - Control Trials (Rivalry Simulation)

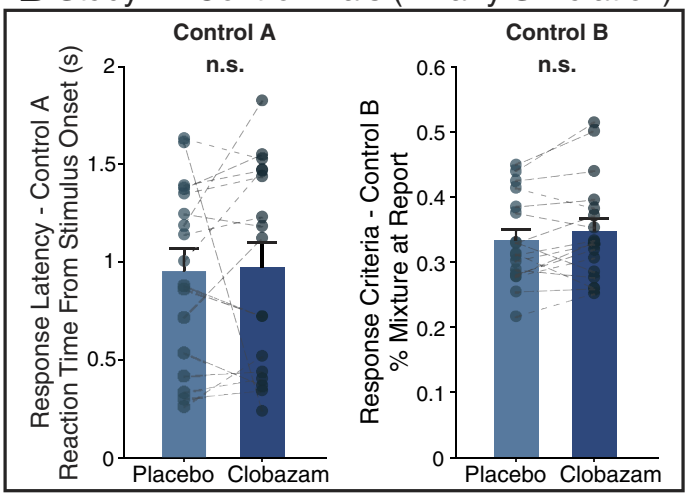

Figure 2. Study $1, \mathrm{GABA}_{\mathrm{A}}$ modulator results. $A$, As predicted, perceptual suppression increased on clobazam compared with placebo days $\left(F_{(1,16)}=5.237, \eta_{\mathrm{p}}^{2}=0.247, p=0.036\right)$. No effect on switch-rate was observed $\left(F_{(1,16)}=0.230, \eta_{\mathrm{p}}^{2}=0.014, p=0.638\right)$. $\boldsymbol{B}$, Critically, rivalry simulation trials were unaffected by the drug manipulation: neither response latencies to detect sudden image transitions $\left(F_{(1,16)}=0.033, \eta_{p}^{2}=0.002, p=0.858\right)$ nor response criteria to judge a gradually changing image as mixed vs dominant $\left(F_{(1,16)}=2.516, \eta_{p}^{2}=0.136, p=0.132\right)$ were changed by clobazam compared with the placebo. In all plots, error bars represent 1 SEM. ${ }^{*} p<0.05$, n.s. $p>0.05$ difference between the conditions.

A Study 2 - Rivalry Trials

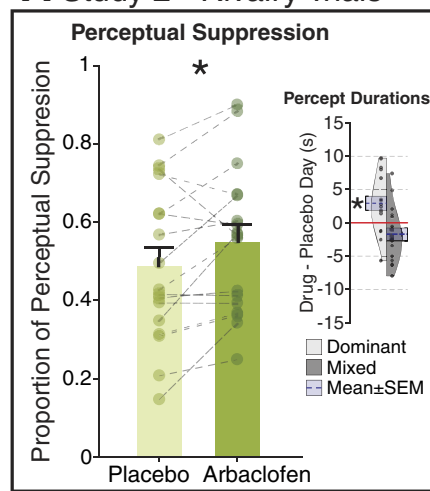

B Study 2 - Control Trials (Rivalry Simulation)

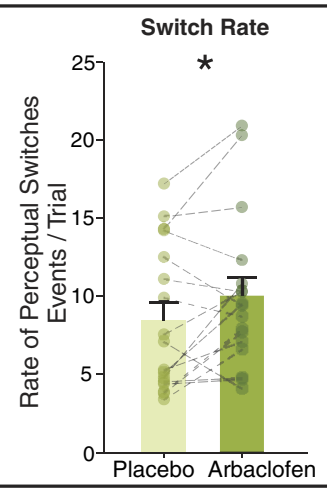

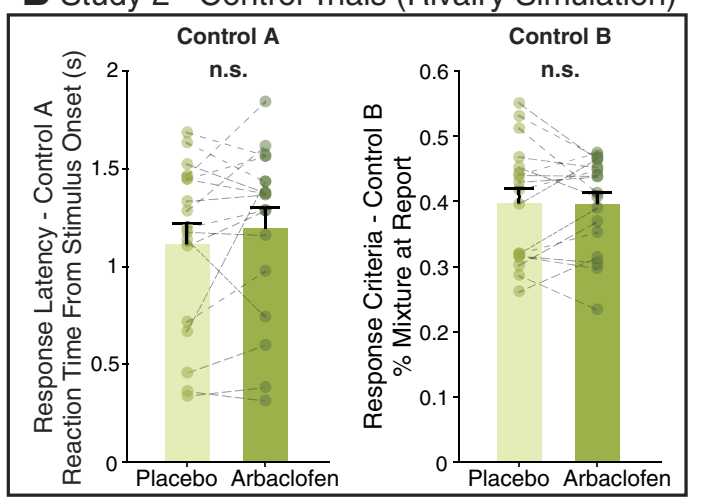

Figure 3. Study $2, \mathrm{GABA}_{\mathrm{B}}$ modulator results. $A$, Again, as predicted, perceptual suppression increased on arbaclofen compared with placebo days $\left(F_{(1,16)}=6.578, \eta_{p}^{2}=0.291, p=0.021\right)$. Arbaclofen also modestly increased perceptual switch-rates during rivalry $\left(F_{(1,16)}=4.909, \eta_{p}^{2}=0.235, p=0.042\right)$. B, Critically, rivalry simulation trials were unaffected by the drug manipulation: neither response latencies to detect sudden image transitions $\left(F_{(1,16)}=1.529, \eta_{\mathrm{p}}^{2}=0.087, p=0.235\right)$, nor response criteria to judge a gradually changing image as mixed versus dominant $\left(F_{(1,16)}=0.002, \eta_{p}^{2}=0.001, p=0.884\right)$ significantly differed between arbaclofen and placebo days. In all plots, error bars represent 1 SEM. ${ }^{*} p<0.05$, n.s. $p>0.05$ difference between the conditions.

A Study 3 - Rivalry Trials

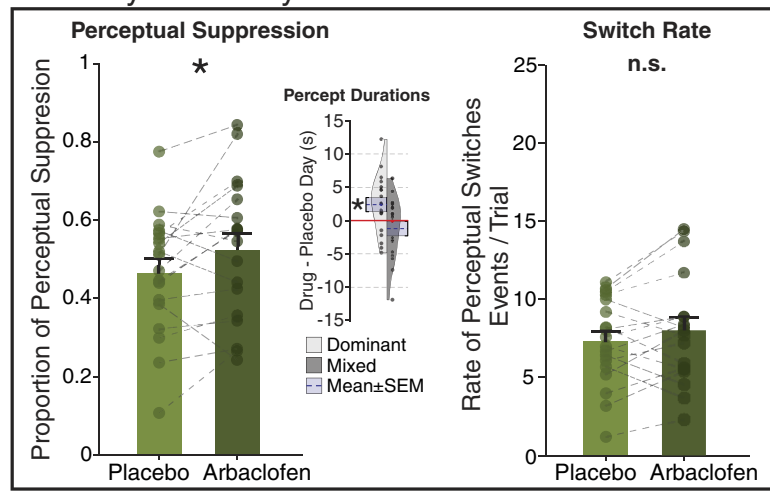

B Study 3 - Control Trials (Rivalry Simulation)

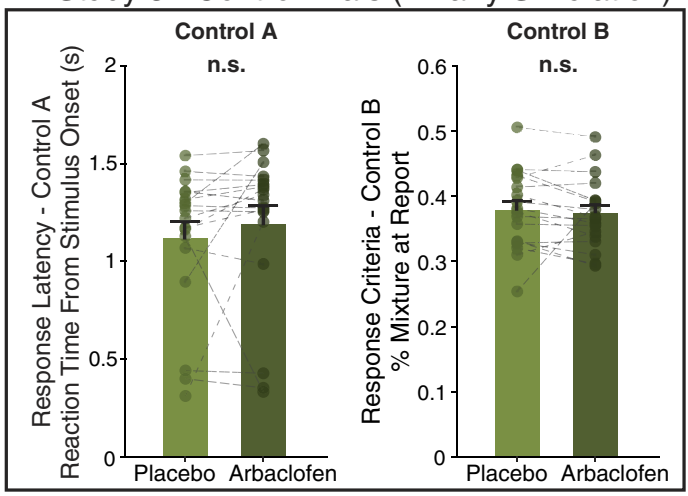

Figure 4. Study $3, G A B A_{B}$ modulator replication results. $A$, Perceptual suppression increased on arbaclofen compared with placebo days, replicating our predicted and previous effects $\left(F_{(1,17)}=\right.$ $\left.5.145, \eta_{\mathrm{p}}^{2}=0.232, p=0.037\right)$. However, arbaclofen did not increase perceptual switch-rates during rivalry $\left(F_{(1,17)}=4.940, \eta_{\mathrm{p}}^{2}=0.122, p=0.142\right) . B$, (ritically, rivalry simulation trials were unaffected by the drug manipulation: response latencies $\left(F_{(1,17)}=0.069, \eta_{p}^{2}=0.004, p=0.796\right)$ and response criteria $\left(F_{(1,17)}=0.214, \eta_{p}^{2}=0.012, p=0.649\right)$. In all plots, error bars represent 1 SEM. ${ }^{*} p<0.05$, n.s. $p>0.05$ difference between the conditions. 


\section{Drug effects on perceptual suppression are stable across experimental time course}

To test whether the strength of our effects grew or waned as a function of time, we first split our data to compare the first and second halves of trials in our experiment (Trials 1-5 and Trials 6-10). Next, we calculated the drug effect on the proportion of suppression for each individual (Proportion of Suppression on Drug - Placebo days) in each half of the data and conducted a repeated-measures ANOVA on Drug Effect with Time as a within-subjects measure. No main effect of Time was observed for our arbaclofen studies: Study $1\left(F_{(1,16)}=0.18, p=0.676\right)$ or Study $3\left(F_{(1,17)}=1.33, p=0.264\right)$. For Study 2, a trend toward an increase in the drug effect was observed $\left(F_{(1,15)}=4.27, p=\right.$ $0.056)$, although this effect did not reach significance.

\section{No reliable effects on switch rates}

Neither GABA modulator reliably affected switch rates during rivalry. In Study 1, no effect on switch-rate was observed for the $\mathrm{GABA}_{\mathrm{A}}$ modulator, clobazam (Clobazam: $8.03 \pm 1.01$ SE switches; Placebo: $7.62 \pm 0.99$ SE switches, $F_{(1,16)}=0.230, \eta_{\mathrm{p}}^{2}=0.014$, $p=0.638$; Fig. $2 A$ ). In Study 2 , the $\mathrm{GABA}_{\mathrm{B}}$, agonist, arbaclofen, modestly increased perceptual switch rates during rivalry (Arbaclofen: $10.07 \pm 1.22$ SE switches; Placebo: $8.48 \pm 1.17 \mathrm{SE}$ switches, $F_{(1,16)}=4.909, \eta_{\mathrm{p}}^{2}=0.235, p=0.042$; Fig. $3 A$ ), however this increase did not replicate in Study 3 (Arbaclofen: $8.03 \pm$ 0.867 SE switches; Placebo: 7.29 \pm 0.675 SE switches, $F_{(1,17)}=$ $4.940, \eta_{\mathrm{p}}^{2}=0.122, p=0.142$; Fig. $4 A$ ). No changes to reversions were observed in any study (all $p$ values $>0.173$ ).

\section{Drug effects are not confounded by shifts in response latency or response criteria}

We next analyzed participants' performance on two rivalry replay conditions to assess any drug effects on participants' response latencies and response criteria, and to determine the potential contribution of these non-perceptual factors to our observed changes in rivalry dynamics. Specifically, we analyzed each participant's report of simulated rivalry transitions on both their drug and placebo days. Sudden transition trials (Control A) provided us with an estimate of participants' motor response latencies (how quickly they press and release a button in response to a stimulus change on the screen). Gradual transition trials (Control B) provided us with an estimate of participants' perceptual decision criteria (the percentage mixture of a stimulus for a participant to report either a mixed or a dominant percept). Again, we used a repeated-measures ANOVA as a within-subjects test of the effect of drugs on behavior.

Neither drug was observed to influence response latencies or response criteria in either study. In Study 1 (clobazam), response latencies (Control A) were not significantly slower on the drug compared with the placebo day $\left(F_{(1,16)}=0.033, \eta_{\mathrm{p}}^{2}=0.002, p=\right.$ 0.858 ), and response criteria (Control $B$ ) remained unchanged $\left(F_{(1,16)}=2.516, \eta_{\mathrm{p}}^{2}=0.136, p=0.132\right.$; Fig. $\left.2 B\right)$. In Study 2 (arbaclofen), again neither response latencies $\left(F_{(1,16)}=1.529, \eta_{\mathrm{p}}^{2}\right.$ $=0.087, p=0.235)$, nor response criteria $\left(F_{(1,16)}=0.002, \eta_{\mathrm{p}}^{2}=\right.$ $0.001, p=0.884$ ) significantly differed between drug and placebo days (Fig. $3 B$ ). In Study 3 (arbaclofen replication), again neither effects on response latencies $\left(F_{(1,17)}=0.069, \eta_{\mathrm{p}}^{2}=0.004, p=\right.$ $0.796)$ nor response criteria $\left(F_{(1,17)}=0.214, \eta_{\mathrm{p}}^{2}=0.012, p=\right.$ 0.649 ) were observed (Fig. $4 B$ ).

Further, the observed drug effects on rivalry were not confounded by changes in response latency or response criteria. To assess this, we re-ran our main analysis, this time including difference scores for each control measure (calculated by subtract- ing performance on drug vs placebo days) as covariates in our main ANOVA. Observed drug effects on rivalry survived after regressing out any effect of the drug on response latencies (Control 1, Study 1: $F_{(1,15)}=5.046, \eta_{\mathrm{p}}^{2}=0.252, p<0.040$; Study 2: $F_{(1,15)}=5.573, \eta_{\mathrm{p}}^{2}=0.271, p<0.032$; Study 3: $F_{(1,16)}=4.769$, $\eta_{\mathrm{p}}^{2}=0.230, p<0.046$ ) or response criteria (Control 2, Study 1: $F_{(1,15)}=5.697, \eta_{\mathrm{p}}^{2}=0.275, p<0.031$; Study 2: $F_{(1,15)}=6.41$, $\eta_{\mathrm{p}}^{2}=0.3 p<0.023$; Study 3: $F_{(1,16)}=5.958, \eta_{\mathrm{p}}^{2}=0.271, p<$ $0.027)$. Overall, these results indicate that our observed drug effects on rivalry dynamics are best attributed to perceptual changes as a result of drug administration, rather than drug effects on non-perceptual measures (response latencies or response criteria).

\section{Baseline rivalry dynamics do not predict magnitude of drug effect}

We observed large individual differences in the proportion of suppression at baseline (placebo days). To test the potential impact of individual differences in rivalry at baseline on the magnitude of our drug effects, we asked whether the base rate (placebo day estimate) of perceptual suppression predicted the magnitude of an individual's drug effect on perceptual suppression. For all three studies, base rate perceptual suppression did not predict the magnitude of drug effect on perceptual suppression (Study $1: \rho=$ $-0.149, p=0.567$; Study 2: $\rho=-0.265, p=0.31$; Study $3: \rho=$ $-0.102, p=0.686)$.

\section{Neither IQ nor BMI predict the magnitude of drug effect}

Two other factors might have mediated our drug effect: individual differences in body mass index (BMI), which likely affects the rate of drug metabolism, and IQ, which might affect task understanding. However, neither measure was observed to predict the magnitude of drug effect on perceptual suppression for any study (BMI: all $p$ values $>0.606$; IQ: all $p$ values $>0.13$ ). Further, the Drug Effect was not significantly different for men versus women in any study (all $p>0.287)$.

\section{$\mathrm{GABA}_{\mathrm{A}}$, but not $\mathrm{GABA}_{\mathrm{B}}$, affects self-reported drowsiness}

Participants in Study 1 reported significant drowsiness after the administration of clobazam, as revealed by comparing drowsiness questionnaire scores between drug and placebo days (mean shift: 0.94 questionnaire points \pm 1.69 points, $p=0.04$ ). No effect of arbaclofen on self-reported drowsiness was observed in either the main study (mean shift: 0.11 questionnaire points \pm 1.41 points, $p=0.074$ ) or arbaclofen replication study (mean shift: -0.33 questionnaire points \pm 1.15 points, $p=0.259$ ). Crucially, the observed drug effects on rivalry were not confounded by changes in self-reported drowsiness. Observed drug effects on perceptual suppression survived after regressing out any effect of the drug on self-reported drowsiness (Control 1; Study 1: $F_{(1,15)}$ $=6.133, \eta_{\mathrm{p}}^{2}=0.290, p<0.026$; Study $2: F_{(1,15)}=7.236, \eta_{\mathrm{p}}^{2}=$ $0.325, p<0.017$; Study 3: $\left.F_{(1,16)}=5.728, \eta_{\mathrm{p}}^{2}=0.264, p<0.029\right)$. These results indicate that drug effects on rivalry cannot be accounted for by non-perceptual effects of the drug on participants' alertness.

\section{Test-retest reliability}

To examine the repeatability of our primary measure, perceptual suppression, we calculated test-retest reliability by correlating performance on drug versus placebo days across individuals in each study. As can be seen in Figure 5, participants' rivalry dynamics were stable across testing days (Study 1, clobazam: $R \mathrm{~s}=$ 0.576, $p=0.016$; Study 2, arbaclofen: $R s=0.887, p<0.001$; 

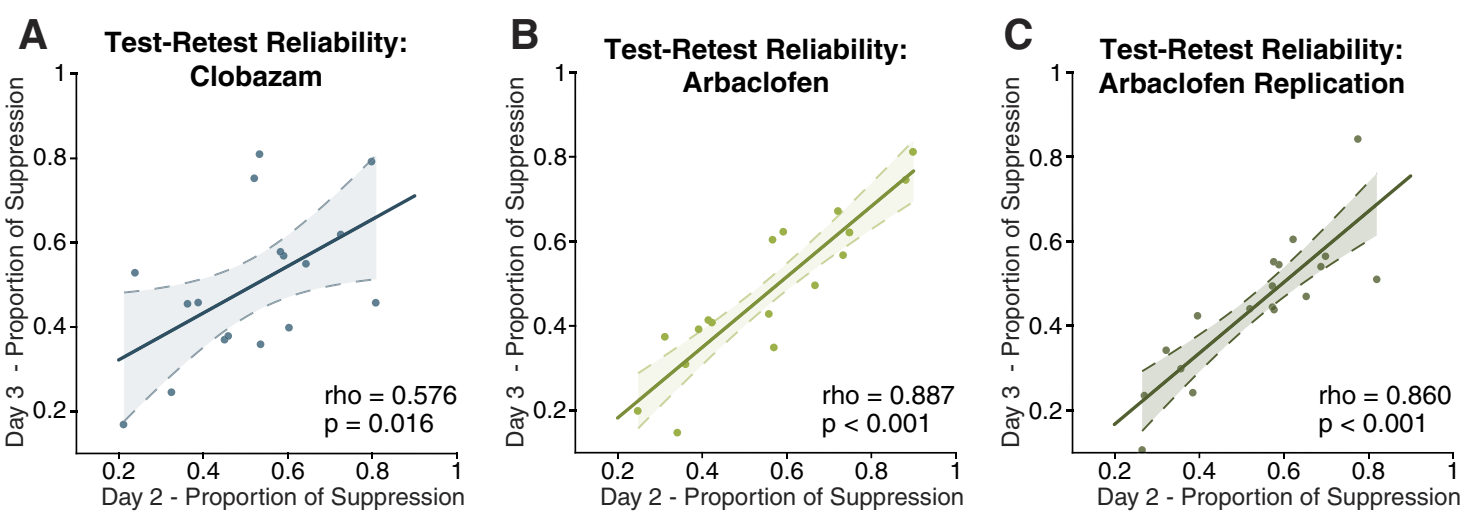

Figure 5. High test-retest reliability of rivalry dynamics. $\boldsymbol{A}$, Participants' rivalry dynamics were stable across clobazam and placebo days $(r=0.576, p=0.016)$, as well as $(\boldsymbol{B})$ arbaclofen and placebo days $(r=0.887, p<0.001)$ and $(C)$ replication study; arbaclofen and placebo days $(r=0.86, p<0.001)$. For example, a fast rivaler on Day 2 remained one of the fastest on Day 3 , even if the entire group became slower after drug administration. High test-retest reliability is in keeping with prior binocular rivalry studies (Miller et al., 2010; Robertson et al., 2016) and further validates the repeatability of our dependent measure. Dashed lines represent the $95 \%$ confidence interval of the regression line.

Study 3, arbaclofen replication: $R s=0.86, p<0.001)$. For example, a fast rivaler on Day 2 remained one of the fastest on Day 3, even if the entire group became slower after drug administration. This finding is in keeping with prior binocular rivalry studies showing high test-retest in rivalry (Miller et al., 2010; Robertson et al., 2016) and underscores the repeatability of our measure. The test-retest reliability was observed to be slightly higher for arbaclofen compared with clobazam (Study 1 vs Study 2: $p=$ 0.047 , Study 1 vs Study 3: $p=0.0873$ ). One reason for the lower test-retest reliability of our Study 1 results might be that due to the relatively long half-life of clobazam, $18 \mathrm{~h}$, the effect of clobazam may not be fully absent on Day 3 when administered on Day 2 (Brogden et al., 1980). It is therefore also possible that our effects would be stronger if Days 2 and 3 were spaced further apart. Notably, a day effect is also typically observed in rivalry, where switch rates decline and perceptual suppression typically decreases during repeated rivalry presentations (Klink et al., 2010). A day effect on perceptual suppression was also observed in all of our studies, but was the smallest for Study 1 (Study 1: $\eta_{\mathrm{p}}^{2}$ $=0.013,5 \%$ of the drug effect; Study $2: \eta_{\mathrm{p}}^{2}=0.450,154 \%$ of the drug effect; Study 3: $\eta_{\mathrm{p}}^{2}=0.489,211 \%$ of the drug effect).

\section{Participant's self-reports of perceptual changes}

It is interesting to note that participants' self-reports, collected via a post-study survey, somewhat reflected measured effects on rivalry dynamics for the $\mathrm{GABA}_{\mathrm{B}}$ agonist arbaclofen. First, when asked "on which day do you think you took the drug?", most participants were correct in their guess: clobazam, 57\% ( $p=$ $0.18)$; arbaclofen, $74 \%(p=0.051)$; arbaclofen replication, $57 \%$ $(p=0.12)$. Next, when asked "did you notice any differences in your experience of binocular rivalry between yesterday and today", most participants reported a perceptual change in suppression and/or switch rate across both drugs (clobazam, 57\%; arbaclofen, 68\%; arbaclofen replication, 62\%). However, the reported perceptual change was not consistently described precisely enough to be interpretable (clobazam, $N=4$; arbaclofen, $N=10$; and arbaclofen replication, $N=4$ ). Thus, it was not possible to assess whether participants' descriptions generally aligned with the findings of our study. Notably, however, the drug effect was not significantly different for participants who correctly guessed the day of the intervention compared with those who did not in any study (Study $1: p=0.10$, Study $2: p=$ 0.95, Study $3: p=0.27$ ).

\section{Participant's self-reports of mixed percepts}

Self-reports of the perceptual quality of mixture states in our study align with the expected perceptual effects of weakened interocular inhibition during rivalry. When asked to freely describe their perceptual experience of mixture states during rivalry, $72 \%$ of participants reported a blended percept, a superimposition between the left- and right-eye images, e.g., "Seeing both objects and both colors overlaid at the same time, as if they were slightly transparent" or "It looks like two overlaying pictures and the transparency settings on them keep changing. So while I can always see both of them, one of the pictures is less transparent than the other, but they are both still some amount of transparent." Such superimposition percepts are posited to correspond to periods of weakened interocular inhibition, in contrast to a different type of mixed percept, piecemeal percepts, which are posited to correspond to weakened inhibition between neurons corresponding to local regions of the visual field (Blake et al., 1992). Based on this hypothesis regarding the neural basis of different mixture percepts during rivalry, the effects observed in our study may particularly reflect GABAergic modulation of interocular inhibition. The observation of greater reported occurrences of superimposition percepts, compared with piecemeal percepts, in our study is consistent with previous studies of rivalry that have shown that high-level object stimuli typically produce significantly more superimposition percepts than piecemeal percepts (Alais and Melcher, 2007; Klink et al., 2010).

\section{Discussion}

We have shown that both $\mathrm{GABA}_{\mathrm{A}}$ - and $\mathrm{GABA}_{\mathrm{B}}$-mediated inhibition increase perceptual suppression during rivalry. These findings are not driven by drug-induced changes in reaction times or response criteria and are replicated in an independent sample of participants $\left(\mathrm{GABA}_{\mathrm{B}}\right)$. Together, these findings demonstrate a causal link between GABAergic inhibition and binocular rivalry dynamics and identify binocular rivalry as an objective marker of GABAergic drug response in the brain.

Our results provide two main insights into the neural mechanisms of bistable perception. First, these findings validate computational models of binocular rivalry, which predict that perceptual suppression covaries with the strength of crossinhibition between neuronal pools coding for left eye and right eye percepts (Klink et al., 2010; Seely and Chow, 2011; Said et al., 2013). MRS findings support this model-based prediction: indi- 
vidual variation in GABA and glutamate levels in early visual cortex correlates with the strength of perceptual suppression (Robertson et al., 2016) as well as the overall duration of dominant percepts during rivalry (van Loon et al., 2013; Pitchaimuthu et al., 2017). Similarly, studies of brief monocular deprivation show that homeostatic reductions in GABA levels in visual cortex post-deprivation predict an increase in the relative predominance of the deprived eye during rivalry (Lunghi et al., 2015) and a reduction in perceptual suppression (Sheynin et al., 2019). Our results complement these previous findings, presenting the first causal link between GABAergic inhibition and the strength of perceptual suppression during binocular rivalry in humans.

Second, our results implicate specific branches of GABAergic inhibition in rivalry. GABA engages two main receptor subtypes in the human brain, $\mathrm{GABA}_{\mathrm{A}}$ and $\mathrm{GABA}_{\mathrm{B}}$. In principle, either of these subtypes might have been implicated in binocular rivalry as both receptors are densely expressed in human visual cortex, with particularly high density in layer 4 of visual cortex (V1; D. March and Shaw, 1993; Muñoz et al., 2001), a putative site of interocular inhibition (Sengpiel et al., 1995). However, these receptors operate on different timescales: $\mathrm{GABA}_{\mathrm{A}}$, an ionotropic ion-channel mediator, initiates fast IPSCs with brief effects $(\sim 20-50 \mathrm{~ms}$; Connors, 1992), whereas $\mathrm{GABA}_{\mathrm{B}}$, a metabotropic receptor, initiates slower IPSCs and has longer lasting effects $(250-1000 \mathrm{~ms}$; Connors, 1992; Benardo, 1994). It is not obvious which of these timescales would be most relevant to rivalry, where perceptual suppression typically occurs on the order of seconds (Blake, 2001), sometimes minutes (Carter et al., 2005). Further, the timescale of inhibition in computational models of rivalry is most aligned with that of fast, $\mathrm{GABA}_{\mathrm{A}}$-mediated IPSCs ( $\sim 50 \mathrm{~ms}$; Li et al., 2017). Our results potentially inform models of rivalry, suggesting that both timescales of inhibition are relevant, and highlighting a novel role for the slower, sustained dynamic of $\mathrm{GABA}_{\mathrm{B}}$ inhibition in the phenomenon.

Our findings are consistent with previous findings in the animal literature. For example, antagonism of local inhibitory circuits in cat primary $\mathrm{V} 1$ using the $\mathrm{GABA}_{\mathrm{A}}$ antagonist bicuculline has been shown to selectively decrease electrophysiological measures of interocular suppression (Sengpiel and Vorobyov, 2005). Further, local administration of the $\mathrm{GABA}_{\mathrm{A}}$ agonist diazepam has been shown to increase the width of ocular dominance columns in the developing cat, suggesting that GABA-mediated inhibition influences the development of local competition between rightand left-eye populations in V1 (Hensch and Stryker, 2004), one anatomical substrate of binocular rivalry along the visual hierarchy (Xu et al., 2016). These findings are consistent with our own, suggesting that GABA influences activity and neural development in rivalry-related circuitry in animals.

To date, causal studies of rivalry in humans have focused on implicating different brain regions in rivalry, with little to say about neurotransmission within these regions. For example, repetitive transcranial magnetic stimulation of parietal sites linked to the top-down stabilization of rivalry dynamics (Carmel et al., 2010; Kanai et al., 2010, 2011), implicate posterior and anterior parietal sites in prolonging or shortening dominance durations, respectively. One previous study attempted to test the effects of a $\mathrm{GABA}_{\mathrm{A}}$ modulator, lorazepam, on rivalry, but participants failed to achieve binocular fusion and thus could not perform rivalry after drug administration (van Loon et al., 2013). Our study also used a $\mathrm{GABA}_{\mathrm{A}}$ modulator, clobazam, but this problem was not observed. We hypothesize that this might be because of the difference in the $\mathrm{GABA}_{\mathrm{A}}$ subunits targeted by lorazepam (subunits 1,4 ) and clobazam (subunits 1,5), where clobazam produces longer-acting effects and significantly less sedation (Sankar, 2012), although clobazam did significantly increase drowsiness in our study.

Pharmacological studies offer an exciting opportunity to directly manipulate neurotransmission in vivo, but there are limitations to this approach. Most notably, drug effects are neuroanatomically global in nature. Thus, it is difficult to attribute our results to inhibitory signaling in a particular visual region of the brain, or specifically to interocular inhibition rather than other visual processes (e.g., sensitivity or adaptation) or even nonvisual processes (e.g., generalized cognitive failures; Sandberg et al., 2014). Further, although we used rivalry simulation trials to control for potential drug effects on participants' response times and perceptual decision criteria and found no drug effects on these two measures, it is possible that our control trials did not fully simulate the degree of decision uncertainty associated with rivalry, which may have been affected if the drugs impacted decision processes in the brain. Acknowledging these limitations, we note that rivalry is a relatively global phenomenon in visual cortex, observed at multiple levels of the visual hierarchy, from V1 (Xu et al., 2016) to IT cortex (Tong et al., 1998). As such, rivalry likely lends itself to a neuroanatomically global manipulation, affording multiple potential sites of reciprocal inhibition for GABAergic modulation to affect. However, future neuroimaging studies are needed to demonstrate that the drugs used in our study specifically affect activity levels in visual areas that are relevant to rivalry, and that these changes predict our observed behavioral effects.

Our results may have important implications for psychiatric research. A major impediment to psychiatric drug development is the lack of robust, objective markers of the neural processes drugs are developed to target (J. S. March and Fegert, 2012; Insel, 2014). Visual tasks may provide particularly promising markers of drug impact in the brain, given that the neural pathways and computational principles underlying many visual processes are well established. Indeed, a number of visual tasks have been shown to be modulated by $\mathrm{GABA}_{\mathrm{A}}$ modulators in previous studies (Fisch et al., 1983; MacNab et al., 1985; Giersch and Herzog, 2004; van Loon et al., 2013) and might also be well suited to probe neural inhibition. One practical benefit of the rivalry paradigm is that it is relatively fast to administer $(\sim 15 \mathrm{~min})$, and thus particularly well suited to probe drug effects that wane over time. Additionally, rivalry dynamics are highly test-retest reliable (Fig. 5; Robertson et al., 2016) and show high heritability in twin studies (Miller et al., 2010), suggesting that the large individual differences observed during rivalry likely map onto stable biological phenomena. Thus, given computational (Klink et al., 2010; Seely and Chow, 2011; Said et al., 2013), correlational (Robertson et al., 2016), and now causal demonstrations of the dependence of rivalry dynamics on GABAergic inhibition, we propose that rivalry may serve as a noninvasive marker of inhibitory signaling in the brain. This tool might shed light on the neural mechanisms of psychiatric conditions thought to be affected by disruptions in inhibition, such as autism (Marín, 2012).

Previous work from our laboratory has demonstrated altered binocular rivalry dynamics in individuals with autism, measured using behavioral report (Robertson et al., 2013, 2016; Freyberg et al., 2015), and recent neuroimaging findings have provided a direct neural readout of altered rivalry dynamics in autism using EEG (Spiegel et al., 2019). Specifically, individuals with autism exhibit slower rivalry switch rates and reduced perceptual suppression, both of which predict autism symptom severity. MRS findings link this replicated and robust perceptual difference to a 
disruption in GABAergic inhibition in visual cortex (Robertson et al., 2016): GABA levels in early visual areas do not predict rivalry dynamics in autism as they do in control individuals, suggesting that GABA fails to effectively drive inhibition in the autistic visual cortex (Robertson et al., 2016). These behavioral results have been replicated in three independent studies (Robertson et al., 2013, 2016; Freyberg et al., 2015; Spiegel et al., 2019), but one previous experiment did not confirm altered rivalry dynamics in autism with unmatched participant groups, although the reported results in this study were consistent with the direction of other studies when participants were matched for age (Said et al., 2013). Together, these findings suggest that binocular rivalry might be able to serve as a noninvasive perceptual marker of the altered inhibitory signaling implicated in autism.

All in all, these results provide direct evidence for a causal link between GABAergic inhibition and binocular rivalry and implicate specific $G A B A$ receptors $\left(G_{A B A}\right.$ and $\left.G A B A_{B}\right)$ in perceptual suppression. More broadly, these results identify binocular rivalry as a simple yet powerful perceptual tool to index GABAergic drug response in the brain, which may further research on psychiatric conditions in which neural inhibition is thought to be affected.

\section{References}

Alais D, Melcher D (2007) Strength and coherence of binocular rivalry depends on shared stimulus complexity. Vision Res 47:269-279.

Antoine MW, Langberg T, Schnepel P, Feldman DE (2019) Increased excitation-inhibition ratio stabilizes synapse and circuit excitability in four autism mouse models. Neuron 101:648-661.e4.

Baker DH, Graf EW (2009) Natural images dominate in binocular rivalry. Proc Natl Acad Sci U S A 106:5436-5441.

Benardo LS (1994) Separate activation of fast and slow inhibitory postsynaptic potentials in rat neocortex in vitro. J Physiol 476:203-215.

Berry-Kravis EM, Hessl D, Rathmell B, Zarevics P, Cherubini M, WaltonBowen K, Mu Y, Nguyen DV, Gonzalez-Heydrich J, Wang PP, Carpenter RL, Bear MF, Hagerman RJ (2012) Effects of STX209 (arbaclofen) on neurobehavioral function in children and adults with fragile $\mathrm{X}$ syndrome: A randomized, controlled, phase 2 trial. Sci Transl Med 4:152ra127.

Berry-Kravis E, Hagerman R, Visootsak J, Budimirovic D, Kaufmann WE, Cherubini M, Zarevics P, Walton-Bowen K, Wang P, Bear MF, Carpenter RL (2017) Arbaclofen in fragile X syndrome: results of phase 3 trials. J Neurodev Disord 9:3.

Blake R (1989) A neural theory of binocular rivalry. Psychol Rev 96:145167.

Blake R (2001) A primer on binocular rivalry, including current controversies. Brain Mind 2:5-38.

Blake R, O'Shea RP, Mueller TJ (1992) Spatial zones of binocular rivalry in central and peripheral vision. Vis Neurosci 8:469-478.

Brascamp JW, Becker MW, Hambrick DZ (2018) Revisiting individual differences in the time course of binocular rivalry. J Vis 18(7):3 1-20.

Brodeur MB, Guérard K, Bouras M (2014) Bank of standardized stimuli (BOSS) phase II: 930 new normative photos. PLoS One 9:e106953.

Brogden RN, Heel RC, Speight TM, Avery GS (1980) Clobazam: a review of its pharmacological properties and therapeutic use in anxiety. Drugs 20: 161-178.

Carmel D, Walsh V, Lavie N, Rees G (2010) Right parietal TMS shortens dominance durations in binocular rivalry. Curr Biol 20:R799-R800.

Carter OL, Presti DE, Callistemon C, Ungerer Y, Liu GB, Pettigrew JD (2005) Meditation alters perceptual rivalry in Tibetan Buddhist monks. Curr Biol 15:R412-R413.

Chen CH, Huang CC, Cheng MC, Chiu YN, Tsai WC, Wu YY, Liu SK, Gau SS (2014) Genetic analysis of GABRB3 as a candidate gene of autism spectrum disorders. Mol Autism 5:36.

Connors BW (1992) $\mathrm{GABA}_{\mathrm{A}}$ - and $\mathrm{GABA}_{\mathrm{B}}$-mediated processes in visual cortex. Prog Brain Res 90:335-348.

Fatemi SH, Reutiman TJ, Folsom TD, Thuras PD (2009) GABAa receptor downregulation in brains of subjects with autism. J Autism Dev Disord 39:223-230.

Fisch HU, Groner M, Groner R, Menz C (1983) Influence of diazepam and methylphenidate on identification of rapidly presented letter strings: diazepam enhances visual masking. Psychopharmacology 80:61-66.

Freyberg J, Robertson CE, Baron-Cohen S (2015) Reduced perceptual exclusivity during object and grating rivalry in autism. J Vis 15(13):11 1-12.

Gallagher RM, Arnold DH (2014) Interpreting the temporal dynamics of perceptual rivalries. Perception 43:1239-1248.

Giersch A, Herzog MH (2004) Lorazepam strongly prolongs visual information processing. Neuropsychopharmacology 29:1386-1394.

Gogolla N, Leblanc JJ, Quast KB, Südhof TC, Fagiolini M, Hensch TK (2009) Common circuit defect of excitatory-inhibitory balance in mouse models of autism. J Neurodev Disord 1:172-181.

Griswold AJ, Ma D, Cukier HN, Nations LD, Schmidt MA, Chung RH, Jaworski JM, Salyakina D, Konidari I, Whitehead PL, Wright HH, Abramson RK, Williams SM, Menon R, Martin ER, Haines JL, Gilbert JR, Cuccaro ML, Pericak-Vance MA (2012) Evaluation of copy number variations reveals novel candidate genes in autism spectrum disorderassociated pathways. Hum Mol Genet 21:3513-3523.

Hanks GW (1979) Clobazam: pharmacological and therapeutic profile. Br J Clin Pharmacol 7:151S-155S.

Hensch TK, Stryker MP (2004) Columnar architecture sculpted by GABA circuits in developing cat visual cortex. Science 303:1678-1681.

Hill DR, Bowery NG (1981) ${ }^{3} \mathrm{H}$-baclofen and ${ }^{3} \mathrm{H}-\mathrm{GABA}$ bind to bicuculline-insensitive GABA B sites in rat brain. Nature 290:149-152.

Insel TR (2014) The NIMH research domain criteria (RDoC) project: precision medicine for psychiatry. Am J Psychiatry 171:395-397.

Kanai R, Bahrami B, Rees G (2010) Human parietal cortex structure predicts individual differences in perceptual rivalry. Curr Biol 20:1626-1630.

Kanai R, Carmel D, Bahrami B, Rees G (2011) Structural and functional fractionation of right superior parietal cortex in bistable perception. Curr Biol 21:R106-R107.

Kaufman AS (1990) Kaufman brief intelligence test: KBIT. Circle Pines, $\mathrm{MN}$ : American Guidance Service.

Klink PC, Brascamp JW, Blake R, van Wezel RJA (2010) Experience-driven plasticity in binocular vision. Curr Biol 20:1464-1469.

Laing CR, Chow CC (2002) A spiking neuron model for binocular rivalry. J Comput Neurosci 12:39-53.

Leopold DA, Logothetis NK (1996) Activity changes in early visual cortex reflect monkeys' percepts during binocular rivalry. Nature 379:549-553.

Li HH, Rankin J, Rinzel J, Carrasco M, Heeger DJ (2017) Attention model of binocular rivalry. Proc Natl Acad Sci U S A 114:E6192-E6201.

Lunghi C, Emir UE, Morrone MC, Bridge H (2015) Short-term monocular deprivation alters GABA in the adult human visual cortex. Curr Biol 25:1496-1501.

Ma DQ, Whitehead PL, Menold MM, Martin ER, Ashley-Koch AE, Mei H, Ritchie MD, Delong GR, Abramson RK, Wright HH, Cuccaro ML, Hussman JP, Gilbert JR, Pericak-Vance MA (2005) Identification of significant association and gene-gene interaction of GABA receptor subunit genes in autism. Am J Hum Genet 77:377-388.

MacNab MW, Foltz EL, Sweitzer J (1985) Evaluation of signal detection theory on the effects of psychotropic drugs on critical flicker-fusion frequency in normal subjects. Psychopharmacology 85:431-435.

March D, Shaw CA (1993) Fetal, neonatal and adult expression of benzodiazepine receptor subtypes in human visual cortex. Eur J Pharmacol 236: 333-336.

March JS, Fegert JM (2012) Drug development in pediatric psychiatry: current status, future trends. Child Adolesc Psychiatry Ment Health 6:7.

Marín O (2012) Interneuron dysfunction in psychiatric disorders. Nat Rev Neurosci 13:107-120.

Miller SM, Hansell NK, Ngo TT, Liu GB, Pettigrew JD, Martin NG, Wright MJ (2010) Genetic contribution to individual variation in binocular rivalry rate. Proc Natl Acad Sci U S A 107:2664-2668.

Muñoz A, DeFelipe J, Jones EG (2001) Patterns of GABABR1a,b receptor gene expression in monkey and human visual cortex. Cereb Cortex 11: $104-113$.

Noest AJ, van Ee R, Nijs MM, van Wezel RJA (2007) Percept-choice sequences driven by interrupted ambiguous stimuli: a low-level neural model. J Vis 7(8):10 1-14.

Orefice LL, Zimmerman AL, Chirila AM, Sleboda SJ, Head JP, Ginty DD (2016) Peripheral mechanosensory neuron dysfunction underlies tactile and behavioral deficits in mouse models of ASDs. Cell 166:299-313.

Pitchaimuthu K, Wu QZ, Carter O, Nguyen BN, Ahn S, Egan GF, McKend- 
rick AM (2017) Occipital GABA levels in older adults and their relationship to visual perceptual suppression. Sci Rep 7:14231.

Piton A, Jouan L, Rochefort D, Dobrzeniecka S, Lachapelle K, Dion PA, Gauthier J, Rouleau GA (2013) Analysis of the effects of rare variants on splicing identifies alterations in GABAA receptor genes in autism spectrum disorder individuals. Eur J Hum Genet 21:749-756.

Robertson CE, Kravitz DJ, Freyberg J, Baron-Cohen S, Baker CI (2013) Slower rate of binocular rivalry in autism. J Neurosci 33:16983-16991.

Robertson CE, Ratai EM, Kanwisher N (2016) Reduced GABAergic action in the autistic brain. Curr Biol 26:80-85.

Said CP, Heeger DJ (2013) A model of binocular rivalry and crossorientation suppression. PLoS Comput Biol 9:e1002991.

Said CP, Egan RD, Minshew NJ, Behrmann M, Heeger DJ (2013) Normal binocular rivalry in autism: implications for the excitation / inhibition imbalance hypothesis. Vision Res 77:59-66.

Sandberg K, Blicher JU, Dong MY, Rees G, Near J, Kanai R (2014) Occipital GABA correlates with cognitive failures in daily life. Neuroimage 87:55-60.

Sandberg K, Blicher JU, Del Pin SH, Andersen LM, Rees G, Kanai R (2016) Improved estimates for the role of grey matter volume and GABA in bistable perception. Cortex 83:292-305.

Sanders SJ, Ercan-Sencicek AG, Hus V, Luo R, Murtha MT, Moreno-De-Luca D, Chu SH, Moreau MP, Gupta AR, Thomson SA, Mason CE, Bilguvar K, Celestino-Soper PB, Choi M, Crawford EL, Davis L, Wright NR, Dhodapkar RM, DiCola M, DiLullo NM, et al. (2011) Multiple recurrent de novo CNVs, including duplications of the 7q11.23 Williams Syndrome Region, Are Strongly Associated with Autism. Neuron 70:863-885.

Sankar R (2012) GABAA receptor physiology and its relationship to the mechanism of action of the 1,5-benzodiazepine clobazam. CNS Drugs 26:229-244.

Seely J, Chow CC (2011) Role of mutual inhibition in binocular rivalry. J Neurophysiol 106:2136-2150.
Sengpiel F, Vorobyov V (2005) Intracortical origins of interocular suppression in the visual cortex. J Neurosci 25:6394-6400.

Sengpiel F, Blakemore C, Harrad R (1995) Interocular suppression in the primary visual cortex: a possible neural basis of binocular rivalry. Vision Res 35:179-195.

Shao Y, Cuccaro ML, Hauser ER, Raiford KL, Menold MM, Wolpert CM, Ravan SA, Elston L, Decena K, Donnelly SL, Abramson RK, Wright HH, DeLong GR, Gilbert JR, Pericak-Vance MA (2003) Fine mapping of autistic disorder to chromosome 15q11-q13 by use of phenotypic subtypes. Am J Hum Genet 72:539-548.

Sheynin Y, Proulx S, Hess RF (2019) Temporary monocular occlusion facilitates binocular fusion during rivalry. J Vis 19(5):23 1-17.

Spiegel A, Mentch JS, Haskins AJ, Robertson CE (2019) Slower binocular rivalry in the autistic brain. Curr Biol 22:2948-2953.

Stanley J, Forte JD, Cavanagh P, Carter O (2011) Onset rivalry: the initial dominance phase is independent of ongoing perceptual alternations. Front Hum Neurosci 5:140.

Tong F, Nakayama K, Vaughan JT, Kanwisher N (1998) Binocular rivalry and visual awareness in human extrastriate cortex. Neuron 21:753-759.

Tong F, Meng M, Blake R (2006) Neural bases of binocular rivalry. Trends Cogn Sci 10:502-511.

van Loon AM, Knapen T, Scholte HS, St John-Saaltink E, Donner TH, Lamme VA (2013) GABA shapes the dynamics of bistable perception. Curr Biol 23:823-827.

Volz M, Kellner HM (1980) Kinetics and metabolism of pyrazolones (propyphenazone, aminopyrine and dipyrone). Br J Clin Pharmacol 10: 299S-308S

Xu H, Han C, Chen M, Li P, Zhu S, Fang Y, Hu J, Ma H, Lu HD (2016) Rivalry-like neural activity in primary visual cortex in anesthetized monkeys. J Neurosci 36:3231-3242. 